\title{
Ethnic influences on weaning diet in the UK
}

\author{
BY JOHN JAMES AND ANITA UNDERWOOD
}

Montpelier Health Centre, Bath Buildings, Bristol BS6 5PT

The UK is a multi-cultural society, and has been enriched by the large-scale immigration that has taken place over the past 50 years. Ethnic minority groups now represent $5.5 \%$ of the total UK population (Office of Population Censuses and Surveys, 1996). Individual groups have brought with them a shared heritage, which includes a common history, a distinct language and characteristic culture. Dietary practice will have been traditionally determined, and weaning diet is no exception. An understanding of the particular weaningdiet practices of ethnic minority groups must be tempered by a recognition of the dynamic relationship individuals and communities develop with the dominant culture. Each family is unique; considerable differences in situations and circumstances prevail in every family, irrespective of whether they all belong to the same ethnic group.

We will argue that, although it is possible to make very broad generalizations about ethnic influences on weaning diet, there is a grave danger in stereotyping children by their ethnic origin. Only by detailed consideration of families' individual circumstances, beliefs, knowledge and requirements will health professionals impact on improving weaning diet for these children. Poverty is a particularly important consideration.

In the present review, we will consider the situation of ethnic minority groups in the UK, review the importance of weaning and the weaning diet, and discuss the many influences on weaning diet. We will discuss the major determinants of weaning practice in specific ethnic minority groups, and review the consequences. We will conclude by considering the ways in which weaning practice may be improved, principles which should be adopted for all children living in the UK, irrespective of their ethnic origin.

\section{ETHNIC MINORITY GROUPS IN THE UK}

The concept of ethnicity was developed to examine the differences in experience of minority migrant groups within a dominant culture. This represented an important move away from racial categorization, which is inherently flawed (originally defined by Blumenbach (Bernal, 1987) in the eighteenth century; he conceived 'Caucasians' as the first and most talented race, originating from Georgia, from whom all other races, 'Mongoloid and Negroid', had 'degenerated'). Ethnicity is a social categorization, referring to a 'shared heritage which includes a common geographical origin and history, distinctive language and characteristic culture' (Susser et al. 1985). There are several caveats: ethnicity is often inappropriately used as a synonym for race (Senior \& Bhopal, 1994); ethnic classifications may aggregate terms covering many cultures, 'Asian' in the UK is often used to describe the diverse populations from South Asia-the Indian Sub Continent, for example; no account is taken of the dynamic relationship between the minority group and the dominant culture, and there is a temptation to view the dominant culture as the standard or norm, 'ethnocentricity' (Senior \& Bhopal, 1994).

The dramatic growth in the population of ethnic minority groups was initiated by the mass immigration from the countries of the 'New Commonwealth' which followed the passing of the 1948 British Nationality Act. The peak of immigration from the Caribbean occurred in the 1960s; immigration from India and Pakistan was at its peak in the late 
1960s and early 1970s. Immigration from Bangladesh, Hong Kong and Africa took place a little later. In more recent years, many immigrants have been asylum seekers; for example, the Ugandan Asians, the refugees from Vietnam, and refugees from Somalia.

Table 1 shows data from the 1991 census (Office of Population Censuses and Surveys, 1996); there were 3015000 members of ethnic minority groups in the UK, representing $5.5 \%$ of the population. Nearly half are from South Asia. Concealed in these figures are an increasing number of individuals, mainly children, resulting from inter-ethnic unions categorized under 'Black other', 'Other Asian', or 'Other other'.

The ethnic composition of the population varies greatly within the UK (Office of Population Censuses and Surveys, 1996). Further analysis of the 1991 census data (Office of Population Censuses and Surveys, 1996) shows that the majority live in the most populous areas, and are more geographically concentrated than the white population. Thus, in Inner London, more than one-quarter of the population are members of an ethnic minority group. In the West Midlands, ethnic minority groups represent $14.6 \%$ of the population; of these, South Asians represent $9.7 \%$ of the population alone. Again, in the East Midlands, Indians form the largest minority group, $28.5 \%$ of the population of the city of Leicester are from ethnic minority groups.

This distribution is unsurprising as the great majority of immigrants settled in inner city areas on arrival in the UK. There is evidence that ethnic minority groups are discriminated against in many aspects of social and economic life, resulting in limited opportunities and lower socio-economic status (Brown, 1984; Susser et al. 1985; Navarro, 1990; Pearson, 1991). Most lived in poverty, and in sub-standard housing; many were isolated by language, and were exposed to a new and different culture. Widespread racism was a further barrier to integration. Inner city areas are often run down, and there are inadequate community resources and amenities. There is underprovision of medical and educational services. There is considerable variation in the degree to which different ethnic minority groups have integrated into the dominant, white culture; as discussed previously,

Table 1. Ethnic minority groups in the UK

(From Office of Population Censuses and Surveys, 1996)

\begin{tabular}{lrr}
\hline & No. & $\%$ Total* \\
\hline Total UK population & 54889000 & \\
White population & 51874000 & 94.5 \\
Ethnic minority groups & 3015000 & 5.5 \\
Black: Total & 891000 & 29.5 \\
Black Caribbean & 500000 & 16.6 \\
Black African & 212000 & 7.0 \\
Black other & 178000 & 5.9 \\
South Asian: Total & 1480000 & 49.1 \\
Indian & 840000 & 27.8 \\
Pakistani & 477000 & 15.8 \\
Bangladeshi & 163000 & 5.5 \\
Chinese and other: Total & 645000 & 21.4 \\
Chinese & 157000 & 5.2 \\
Other Asian & 198000 & 6.6 \\
Other & 290000 & 9.6 \\
\hline
\end{tabular}

*For white population and ethnic minority groups this represents the percentage of the total UK population; for all other values this represents the percentage of the total for ethnic minority groups. 
many South Asian communities have flourished (particularly in the Midlands and South London) and retained much of their original culture. Furthermore, differences in 'first ' and 'second generation' individuals are now apparent; increasing numbers have spent their lives growing up in the UK. Inter-ethnic unions are increasingly common, particularly in Black African-Caribbean groups (Office of Population Censuses and Surveys, 1996).

Thus, when considering ethnic minority groups, the influence of individual circumstances (where economic and social circumstances have been shown to affect health outcomes in later life; Ben-Shlomo \& Davey-Smith, 1991), experiences and length of time in the UK, as well as country of birth must be taken into account. The temptation to stereotype by ethnic origin must be avoided.

\section{IMPORTANCE OF WEANING AND THE WEANING DIET IN THE UK}

Weaning is the process of expanding the diet to include foods and drinks other than breast milk or infant formula, to enable infants to meet their changing nutritional needs at a period of rapid growth and development (Department of Health, 1994). Nutrition in the early years of life is a major determinant of growth and development and has considerable influence on adult health (Barker, 1990). The time of weaning coincides with the maturation of the infant's physiology to cope with the energy- and nutrient-dense diet associated with solid feeds; experience of new tastes and textures is also a prerequisite for the infant's development. Untimely and inappropriate introduction of weaning, therefore, can result in both behavioural and health problems for the child, as well as stress in the family.

The Committee on Medical Aspects of Food Policy (COMA) report Weaning and the Weaning Diet was published by Department of Health (1994). The report recommends that the majority of children should not be given solids before the age of 4 months, and that a mixed diet should be offered by the age of 6 months, enabling infants to experience new textures and tastes. Semi-solid foods should be given from a spoon, and not mixed with drinks in a bottle. This ensures that infants develop the ability to form a bolus and swallow solids. These skills must be encouraged if the infant is to learn to chew. At 7 months, infants can shut their mouths and refuse to feed; a problem if they have not been exposed to new textures and tastes before.

As well as the process of weaning, the COMA report (Department of Health, 1994) considered the energy requirements of the infant, the need for vitamins, mineral requirements (in particular Fe), and milk and other drinks.

The COMA report (Department of Health, 1994) also highlighted the paucity of data on weaning diets, particularly in infants from ethnic minority groups.

\section{INFLUENCES ON WEANING DIET}

Weaning practice depends principally on the knowledge, beliefs, attitudes and resources of the infant's parents. Although common to all groups, ethnic minority groups are likely to experience particular problems (Table 2).

Cultural and religious beliefs are powerful influences on weaning and dietary practice; dietary restrictions (many groups adhere to vegetarian or vegan diets) can result in considerable difficulties. Mothers newly arrived in the UK may find difficulty in obtaining foods they are familiar with, and experience difficulty in learning new ways of preparing foods they are encountering for the first time. Many mothers who are members of ethnic minority groups will feel isolated and deprived of support from the community. Poverty 
Table 2. Influences on weaning practices

\begin{tabular}{lll}
\hline Knowledge & Education \\
& Availability of appropriate weaning information \\
& Influence of family, friends, media, health professionals \\
& Religion \\
& Culture \\
& Retaining old traditions \\
& Isolation \\
& Psychological state \\
& Domestic circumstances \\
& Socio-economic status \\
& Poverty limiting choice of foods \\
& Availability of familiar foods \\
& Family support \\
\hline
\end{tabular}

can impose considerable restrictions on the opportunity for food choice and experimentation (National Children's Homes, 1991).

Many may experience problems in obtaining advice from health professionals, through a combination of inaccessibility of appropriate primary health care services, language or cultural difficulties, and the often inadequate dietary knowledge of health professionals themselves. There is evidence, however, that mothers do expect health professionals to give clear guidelines about weaning diet; a survey of 300 mothers in 1991 showed that $94 \%$ expected clear guidelines about weaning diet, and felt that health visitors and general practitioners should offer advice automatically. Only $25 \%$ of the mothers had received weaning advice; of those given weaning advice, more than half found the advice confusing and unhelpful (SMA market research in 1991; SMA Nutrician, Taplow, Berks., unpublished results). In a multi-cultural Bristol general practice, mothers identified nutritional advice as their principal health need (James, 1995).

\section{SPECIFIC ETHNIC MINORITY GROUPS}

A knowledge of the background of ethnic minority groups is essential if weaning difficulties are to be identified, and appropriate management introduced. Dietary laws are imposed by many religions (see Table 3 ). These relate principally to the avoidance of certain (or all) animal products; varying classifications of foods may dictate when particular foods should be taken or avoided. Periods of fasting (Ramadan) may result in nutritional difficulties if practised strictly.

Cultural traditions may determine the time of introduction of weaning, as well as particular practices. Furthermore, economic circumstances may force mothers back to work soon after the birth of their baby, resulting in low breast-feeding rates, particularly in Southern Asian communities in the UK.

\section{CONSEQUENCES OF WEANING PRACTICE IN ETHNIC MINORITY GROUPS}

\section{Breast feeding}

Low rates of breast-feeding in immigrant communities are described, but match low rates across populations in inner-city areas. Of (principally) Punjabi infants, $21 \%$ were breastfed, as were $48 \%$ Nigerian and $2 \%$ Chinese infants living in Glasgow in 1974-6. These 
Table 3. Dietary restrictions imposed by cultural and religious backgrounds among ethnic minority groups in the $U K$

\begin{tabular}{|c|c|c|}
\hline Ethnic group & Religion & Dietary restrictions \\
\hline $\begin{array}{l}\text { Southern Asian } \\
\text { Indians }\end{array}$ & $\begin{array}{l}\text { Hindus } \\
\text { Gujaratis: Mainly Hindu } \\
\text { A few Moslems } \\
\text { Sikhs (Punjab) }\end{array}$ & $\begin{array}{l}\text { No beef, usually vegetarian } \\
\text { Strictly vegan } \\
\text { No pork, Halal } \\
\text { Pork, no beef, often vegetarian }\end{array}$ \\
\hline Pakistan & Muslim & No pork, Halal, eggs, dairy \\
\hline Bangladesh & Muslim & No pork, Halal, few eggs, no dairy \\
\hline $\begin{array}{l}\text { Chinese and Vietnamese } \\
\text { Many refugees, families split up } \\
\text { Traditional medicine } \\
\text { Glucose-6-phosphate dehydrogenase ( } E C 1 \text {. } \\
\text { Heating and cooling foods } \\
\text { Children weaned on rice porridge (congee) } \\
\text { Rarely drink milk }\end{array}$ & , lactase deficiency & \\
\hline
\end{tabular}

rates contrast with the high rates (in excess of $80 \%$ ) of breast-feeding in their countries of origin (Goel et al. 1978). In the same study, just $1 \%$ of the indigenous population were breast-fed. More recent studies from Southern Asian groups living in Bradford (Sahota, 1991), Leeds (Williams et al. 1989) and London (Bangladeshi) (Treuherz et al. 1982) showed similar low rates of breast-feeding which (excepting Leeds) mirrored the low rates of local white mothers.

\section{Introduction of solids}

The age at which solids are first introduced reflects the patterns for the population in innercity areas, although there is considerable variation between studies (Warrington \& Storey, 1988).

Many Southern Asian and Chinese minority groups receive large amounts of infant formula or cow's milk as their main source of nutrition for an inappropriately long time. When cow's milk dominates the diet in infancy (Harris et al. 1983; Sahota, 1991; Harbottle \& Duggan, 1992), Fe deficiency is a considerable risk (see p. 126). Prolonged bottle feeding and the addition of sugar or honey to drinks is common practice among Southern Asian communities. In the study from Leeds (Williams et al. 1989) more than $90 \%$ of the Asian children were using feeding bottles at 24 months.

Two studies, from Rochdale (Warrington \& Storey, 1988) in 1982 and Sheffield (Duggan et al. 1991) compared white children with Southern Asian ethnic minorities; both studies found lower intakes of energy and protein in the minority groups. In Sheffield, fat provided $40 \%$ of energy by the child's second birthday (Duggan et al. 1991).

\section{Vegetarian and vegan diets}

Although carefully-planned vegetarian diets can give adequate nutrition, they are likely to be low in energy and bulky, so children may not consume foods in adequate volumes. Vegan diets tend to be associated with smaller and lighter meals than those of the general 
population (Sanders, 1988). Legumes, bran products and seeds may contain high levels of phytates and other inhibitors which reduce the bioavailability of certain minerals; $\mathrm{Fe}, \mathrm{Zn}$ and $\mathrm{Cu}$ in particular. Additional vitamin $\mathrm{C}$ will, however, increase the absorption of these minerals (Hallberg et al. 1986). Riboflavin and vitamin $B_{12}$ supplements are essential for vegan diets.

\section{Vitamin D deficiency}

Vitamin D is provided principally through synthesis in the skin, but does occur naturally in oily fish and eggs. Children from South Asia are at particular risk of vitamin D deficiency (Grindulus et al. 1986) since their mothers are at risk (Department of Health and Social Security, 1980), they may be subject to dietary restrictions, are traditionally shielded from sunlight, and have reduced vitamin D synthesis as a result of their pigmented skin.

A Bristol study described seven cases of nutritional rickets in one general practice among Rastafarian infants who had been brought up on a strictly vegan diet (James et al. 1985). Interestingly, more detailed examination of the traditional 'Ital' diet the mothers had followed revealed that 'small fishes less than four inches long' were permitted (allowing the provision of the necessary vitamin D).

The association between rickets and poverty is increasingly apparent, however, with an increase in the number of reported cases of nutritional rickets in inner-city children. Vitamin D levels of 2000 inner-city children (aged 24 months) from ethnic minority groups (with 400 white controls) will be available from the Department of Health nutritional study (Department of Health, 1994) to be published in 1997.

\section{Iron-deficiency anaemia (IDA)}

IDA is the most commonly reported nutritional disorder in childhood, and is an important condition since in toddlers it is associated with psychomotor delay (Auckett et al. 1986; Idjradinata \& Pollitt, 1993). Psychomotor development in anaemic toddlers has been shown to be improved by treatment with Fe (Walter et al. 1990; Iyer \& Lonnerdal, 1993), although there is evidence that the deficits may not be fully reversible in the longer term, in spite of treatment (Walter et al. 1990).

Fe deficiency may result from inadequate Fe stores at birth (due to prematurity, smallfor-dates, or severe maternal anaemia in pregnancy), but the major cause of IDA is inadequate intake of $\mathrm{Fe}$ in the weaning period. Although the total Fe content of breast milk is low, it has high bioavailability due to their presence of human lactoferrin which binds with two molecules of $\mathrm{Fe}^{3+}$ to facilitate absorption (more than $50 \%$ is absorbed). In contrast, bovine lactoferrin is not so effective in this way in human subjects, thus absorption from cows' milk or milk formula is much less (Iyer \& Lonnerdal, 1993). After the age of 6 months, the Fe available from breast milk is inadequate to meet the infants' increasing needs, so additional sources of $\mathrm{Fe}$ are needed.

The measured Fe content of foods does not correspond to the amount absorbed; haemFe (found in meat) is better absorbed than non-haem-Fe (found in plants), and many foods contain inhibitors of $\mathrm{Fe}$ absorption. Examples are phytic acid found in cereals, legumes and other vegetables, tannin found in tea and polyphenols in spinach (Spinacia oleracea). Conversely, vitamin C will assist the absorption of Fe (Hallberg et al. 1986), as does the presence of protein.

For these reasons, infants who are not breast-fed, who are given cow's milk in the first months of life, who are weaned late, or who are given vegetarian diets are at risk of IDA 
Table 4. Prevalance of anaemia (haemoglobin $<110 \mathrm{~g} \Omega$ ) in infants in the $U K$ (From James \& Laing, 1994)

\begin{tabular}{|c|c|c|c|c|c|}
\hline Location & Year of study & No. of infants & Age (months) & Ethnic group & $\%$ Anaemic \\
\hline Bradford & 1983 & 598 & $6-48$ & $\begin{array}{l}\text { White } \\
\text { Southern Asian }\end{array}$ & $\begin{array}{l}12 \\
28\end{array}$ \\
\hline Birmingham & 1983 & 134 & $21-23$ & Southern Asian & 31 \\
\hline Birmingham & 1984 & 470 & $17-19$ & $\begin{array}{l}\text { White } \\
\text { Southern Asian }\end{array}$ & $\begin{array}{l}18 \\
31\end{array}$ \\
\hline London & 1987 & 148 & $8-24$ & $\begin{array}{l}\text { White } \\
\text { Southern Asian } \\
\text { African-Caribbean }\end{array}$ & $\begin{array}{l}17 \\
26 \\
18\end{array}$ \\
\hline Bristol & 1988 & 122 & $12-24$ & $\begin{array}{l}\text { White } \\
\text { African-Caribbean }\end{array}$ & $\begin{array}{l}18 \\
25\end{array}$ \\
\hline $\begin{array}{l}\text { Sheffield } \\
\text { UK (NDNS) }\end{array}$ & $\begin{array}{l}1989 \\
1992\end{array}$ & $\begin{array}{l}138 \\
300\end{array}$ & $\begin{array}{r}4-40 \\
18-29\end{array}$ & Southern Asian & $\begin{array}{l}11 \\
12\end{array}$ \\
\hline
\end{tabular}

NDNS, National Diet and Nutrition Survey.

(Idjradinata \& Pollitt, 1993). As outlined earlier, many infants, especially those from Southern Asia, fall into one or more of these categories.

Table 4 lists recent studies on the prevalence of anaemia in infants and young children in the UK. Although the studies do not involve large numbers of children, children from the Caribbean, and Southern Asia appear to have a higher prevalence of IDA (up to $25 \%$ (James et al. 1989) and $31 \%$ (Department of Health and Social Security, 1980) respectively). None of the studies attempted to measure the impact of socio-economic deprivation as an independent variable, although a study in Newcastle (Wright et al. 1989) found a higher prevalence of IDA in 'deprived' children than in those who were from 'affluent' backgrounds (although these children were older, their age-range was 9-15 years). The National Diet and Nutrition Survey (for the Ministry of Agriculture, Fisheries and Food) examined 300 toddlers selected as representative of the UK population aged between 18 and 29 months, and found $12 \%$ were anaemic (Gregory et al. 1995).

There has been considerable debate about the best means of preventing Fe deficiency (Dallman, 1990; Oski, 1993). The Fe status of infants can be improved through dietary modification, through fortification of foods, or by giving supplementary Fe.

Dietary education given must be sensitive to the culture, beliefs and resources of families; the prevalence of IDA in African-Caribbean toddlers has been reduced in a general practice setting in Bristol (James et al. 1989), but a recent large-scale, carefullycontrolled study in Birmingham failed to reduce the prevalence of IDA in South Asian toddlers (Child et al. 1997). The mothers received a structured programme of health education over an 18-month period. There was no difference in the prevalence of IDA at 18 months in 499 children whose mothers had, or had not, received dietary advice. Of the children brought up on a vegetarian diet, $36 \%$ were anaemic at 18 months.

Routine supplementation with Fe may be considered, but there are concerns about overdosing (potential of poisoning) and gastrointestinal side-effects. Compliance may also prove to be a problem. Fortification of foods with $\mathrm{Fe}$ is effective; children given infant formula for the first 12 months of life are unlikely to develop IDA (Moffat et al. 1987).

Screening for IDA has been proposed as a means of identifying and preventing IDA (Hall, 1989). Screening may prove an important means of identifying the condition in atrisk groups (such as children from ethnic minority groups), but as the natural history of IDA is not clear, screening should not be introduced universally (James et al. 1995). 


\section{Dental health}

Caries is the most important dental problem in young children and there has been a halt in the declining trend in the incidence of caries in the UK (Holt et al. 1988). Caries is more common in children living in poverty, from single-parent families, and in children from Southern Asia, particularly those who are Muslim, and whose parents speak little or no English (Paul \& Bradnock, 1986; Bedi, 1989).

Caries, although slow to progress, may destroy the tooth very rapidly. This condition termed 'rampant', or nursing caries, is associated with the prolonged use of sweetened drinks in bottles or reservoir feeders. This practice is common in Southern Asian inner-city communities and accounts for the high prevalence of caries in these children (Ripa, 1988).

\section{THE WAY FORWARD}

Many infants in ethnic minority groups are receiving a sub-optimal weaning diet. There is a clear need to provide better information for mothers, and this must be sensitive to the expectations, beliefs, culture, attitudes, knowledge and resources of the family. Health professionals must have a detailed knowledge of the background and culture of the ethnic minority groups in the community, and must work in partnership with parents, empowering them rather than dictating appropriate weaning practice. Health professionals (principally health visitors) must have access to expert dietary advice (ideally from community dieticians), and ensure that consistent advice is given. The primary health care team would seem ideally placed to deliver consistent messages, yet few general practices have weaning diet policies (James, 1995). The opportunity exists to work with other community workers, link workers, food co-operatives and other voluntary organizations.

The range of commercial weaning foods should be enlarged to offer a wider choice to those with specific cultural or religious dietary requirements; these foods could be fortified where appropriate.

More effective strategies for public education are needed. This requires multi-sectorial contributions, involving public health departments, health promotion, education and the media.

Finally, there is a need for a greater knowledge base; there have been few recent studies of infant weaning and feeding practices in ethnic minority groups. Moreover, these earlier studies cannot take into account the changes in dietary practice that have occurred in ethnic minority groups, particularly second-generation communities, since they settled in the UK. The Department of Health has commissioned a survey of weaning and feeding practices and growth rates in babies from Gujarati, Punjabi, Pakistani and Bangladeshi communities (Department of Health, 1994). Importantly they will be compared with a group of white babies resident in the same localities. All will be followed up for 15 months. The results will be available in 1997.

\section{CONCLUSION}

Ethnic minority groups have enriched our society, yet many still live in considerable socioeconomic deprivation. This, and their cultural and religious heritage, may impose a significant disadvantage on weaning infants. We need to increase our knowledge of current weaning practice of ethnic minority groups, for improved education of health professionals, and for sensitive weaning advice for families who should be seen as individuals rather than simply members of an ethnic minority group. 


\section{REFERENCES}

Auckett, M. A., Parks, Y. A., Scott, P. H. \& Wharton, B. A. (1986). Treatment with iron increases weight gain and psychomotor development. Archives of Disease in Childhood 61, 849-857.

Barker, D. J. P. (1990). The foetal and infant origins of adult disease. British Medical Journal $301,1111$.

Bedi, R. (1989). Ethnic indicators of dental health for young Asian school-children resident in areas of multiple deprivation. British Journal of Dentistry 166, 331-334.

Ben-Shlomo, Y. \& Davey-Smith, G. (1991). Deprivation in infancy or adult life: which is the more important for mortality risk? Lancet 337, 530-534.

Bernal, M. (1987). Black Athena: The Afroasiatic Roots of Classical Civilisation. London: Vintage.

Brown, C. (1984) Black and White Britain: The Third PSI Survey. London: Heinemann.

Child, F., Auckett, M. A., Darbyshire, P., Ilet, S. \& Livera, L. N. (1997). Does nutritional education work in preventing iron deficiency in the inner-city. Archives of Disease in Childhood (In the Press).

Dallman, P. R. (1990). Progress in the prevention of iron deficiency anaemia in infants. Acta Paediatrica Scandinavica 365, Suppl., 28-37.

Department of Health and Social Security (1980). Rickets and Osteomalacia. Report on Health and Social Subjects no. 19. London: H.M. Stationery Office.

Department of Health (1994). Weaning and the Weaning Diet. Report on Health and Social Subjects no. 45. London: H.M. Stationery Office.

Duggan, M. B., Steel, G., Elwys, G., Harbottle, L. \& Nobel, C. (1991). Iron status, energy intake and nutritional status of healthy young Asian children. Archives of Disease in Childhood 66, 1386-1389.

Goel, K. M., House, F. \& Shanks, R. A. (1978). Infant feeding practices among immigrants in Glasgow. British Medical Journal 2, 1181-1183.

Gregory, J. R., Collins, D. L., Davies, P. S. W., Clarke, P. C. \& Hughes, J. M. (1995). National Diet and Nutrition Survey of Children Aged One and $a$ Half and Four and a Half Years. vol. 1: Report of the Diet and Nutrition Survey. London: H.M. Stationery Office.

Grindulus, H., Scott, P. H., Bolton, N. R. \& Wharton, B. A. (1986). Combined efficiency of iron and vitamin D in Asian toddlers. Archives of Disease in Childhood 61, 843-848.

Hall, D. M. (1989). Health for All Children: A Programme of Child Health Surveillance, pp. 34-46. Oxford: Oxford University Press.

Hallberg, L., Brune, M. \& Rossander, L. (1986). Effects of ascorbic acid on iron absorption from different types of meals. Human Nutrition: Applied Nutrition 40A, 97-113.

Harbottle, L. \& Duggan, M. B. (1992). Comparative study of the dietary characteristics of Asian toddlers with iron deficiency in Sheffield. Journal of Human Nutrition and Dietetics 5, 351-361.

Harris, R. J., Armstrong, D., Ali, R. \& Loynes, A. (1983). Nutritional survey of Bangladeshi children under the age of five years in the London Borough of Tower Hamlets. Archives of Disease in Childhood 58, 428-432.

Holt, R. D., Joels, D., Bulman, J. \& Maddick, I. H. (1988). A third study of caries in pre-school aged children in Camden. British Dental Journal 165, 87-91.

Idjradinata, P. \& Pollitt, E. (1993). Reversal of developmental delays in iron deficient infants treated with iron. Lancet 341, 1-4.

Iyer, S. \& Lonnerdal, B. (1993). Lactoferrin, lactoferrin receptors and iron metabolism. European Journal of Clinical Nutrition 47, 232-241.

James, J. (1995). Nutrition in the normal infant: opportunities in primary care. In Nutrition in Child Health, pp. 43-49 [D. P. Davies, editor]. London: Royal College of Physicians.

James, J. \& Laing, G. (1994). Iron deficiency anaemia. Current Pediatrics 4, 33-37.

James, J., Lawson, P., Male, P. \& Oakhill, A. (1989). Preventing iron deficiency in pre-school children by implementing an educational and screening programme in an inner city practice. British Medical Journal 299, 838-840.

James, J. A., Clark, C. \& Ward, P. S. (1985). Screening Rastafarian children for nutritional rickets. British Medical Journal 291, 239-242.

James, J. A., Laing, G. J. \& Logan, S. (1995). Changing patterns of iron deficiency anaemia in the second year of life. British Medical Journal 311, 230.

Moffat, M. E. K., Longstaffe, S., Besant, J. \& Dureski, M. A. (1987). Prevention of iron deficiency and psychomotor decline in high-risk infants through use of iron fortified infant formula: a randomised clinical trial. Journal of Pediatrics 111, 813-816.

National Children's Homes (1991). NCH Poverty and Nutrition Survey. London: National Children's Homes.

Navarro, V. (1990). Race or class versus race and class: mortality differentials in the United States. Lancet 336, 8725 .

Office of Population Censuses and Surveys (1996). Size, structure and growth of the ethnic minority populations. In Ethnicity in the 1991 Census, vol.1 [D. Coleman and J. Salt, editors]. London: H.M. Stationery Office.

Oski, F. A. (1993). Iron deficiency anaemia in infancy and childhood. New England Journal of Medicine 329, 190-193.

Paul, P. F. \& Bradnock, G. (1986). The dental health of Asian and Caucasian four and five year old children resident in Coventry. Community Dental Health 3, 275-285. 
Pearson, M. (1991). Ethnic differences in infant health. Archives of Disease in Childhood 66, 88-90.

Ripa, L. W. (1988). Nursing caries; a comprehensive review. Paediatric Dentistry 10, 268-282.

Sahota, P. (1991). Feeding Baby: Inner City Practice. Bradford: Horton Publishing.

Sanders, T. A. (1988). Growth and development of British vegan children. American Journal of Clinical Nutrition 48, 822-825.

Senior, P. A. \& Bhopal, R. (1994). Ethnicity as a variation in epidemiological research. British Medical Journal 309, 327-330.

Susser, M. W., Watson, W. \& Hopper, K. (1985). Sociology in Medicine. New York: Oxford University Press.

Treuherz, J., Cullinan, T. R. \& Saunders, D. I. (1982). Determinants of infant-feeding practice in East London. Human Nutrition: Applied Nutrition 36, 281-286.

Walter, T., de Andraca, I., Castillo, M., Rivera, F. \& Cobo, C. (1990). Cognitive effect at five years of age in infants who were anaemic at 12 months; a longitudinal study. Pediatric Research 28, 295.

Warrington, S. M. \& Storey, D. M. (1988). Comparative studies on Asian and Caucasian children. 2: Nutrition, feeding practices and health. European Journal of Clinical Nutrition 42, 69-80.

Williams, S. A., Sahota, P. \& Fairpoo, C. G. (1989). Infant feeding practices within white and Asian communities in inner city Leeds. Journal of Human Nutrition and Dietetics 2, 325-338.

Wright, C. M., Reading, R. F., Halse, P. C. \& Watson, J. G. (1989). Iron deficiency in adolescents. British Medical Journai 298, 1035. 